\title{
BMJ
}

\section{Effect of fish oil on arrhythmias and mortality: systematic review}

\author{
Hernando León, postgraduate in internal medicine and former postdoctoral clinical research fellow, ${ }^{1,2}$ \\ Marcelo C Shibata, associate clinical professor, ${ }^{1,2}$ Soori Sivakumaran, associate clinical professor of \\ medicine, ${ }^{1,2}$ Marlene Dorgan, head, ${ }^{3}$ Trish Chatterley, research librarian, ${ }^{3}$ Ross T Tsuyuki, professor of \\ medicine (cardiology) and director ${ }^{1,2}$
}

\begin{abstract}
${ }^{1}$ Epidemiology Coordinating and Research (EPICORE) Centre, Edmonton, $A B$, Canada

${ }^{2}$ Department of Medicine, Division of Cardiology, Faculty of Medicine and Dentistry, University of

Alberta, 220 College Plaza,

Edmonton, AB, Canada T6G 2C8

${ }^{3}$ Institute of Health Economics and John W Scott Health Sciences Library, University of Alberta

Correspondence to: R T Tsuyuki ross.tsuyuki@ualberta.ca
\end{abstract}

Cite this as: BMJ 2009;338:a2931 doi:10.1136/bmi.a2931

\section{ABSTRACT}

Objective To synthesise the literature on the effects of fish oil-docosahexaenoic acid (DHA) and eicosapentaenoic acid (EPA)—on mortality and arrhythmias and to explore dose response and formulation effects.

Design Systematic review and meta-analysis.

Data sources Medline, Embase, the Cochrane Library, PubMed, CINAHL, IPA, Web of Science, Scopus, Pascal, Allied and Complementary Medicine, Academic OneFile, ProQuest Dissertations and Theses, Evidence-Based Complementary Medicine, and LILACS.

Studies reviewed Randomised controlled trials of fish oil as dietary supplements in humans.

Data extraction The primary outcomes of interest were the arrhythmic end points of appropriate implantable cardiac defibrillator intervention and sudden cardiac death. The secondary outcomes were all cause mortality and death from cardiac causes. Subgroup analyses included the effect of formulations of EPA and DHA on death from cardiac causes and effects of fish oil in patients with coronary artery disease or myocardial infarction.

Data synthesis 12 studies totalling 32779 patients met the inclusion criteria. A neutral effect was reported in three studies $(n=1148)$ for appropriate implantable cardiac defibrillator intervention (odds ratio $0.90,95 \%$ confidence interval 0.55 to 1.46$)$ and in six studies $(n=31111)$ for sudden cardiac death $(0.81,0.52$ to 1.25$) .11$ studies $(n=32439$ and $n=32519)$ provided data on the effects of fish oil on all cause mortality $(0.92,0.82$ to 1.03$)$ and a reduction in deaths from cardiac causes $(0.80,0.69$ to 0.92). The dose-response relation for DHA and EPA on reduction in deaths from cardiac causes was not significant. Conclusions Fish oil supplementation was associated with a significant reduction in deaths from cardiac causes but had no effect on arrhythmias or all cause mortality. Evidence to recommend an optimal formulation of EPA or DHA to reduce these outcomes is insufficient. Fish oils are a heterogeneous product, and the optimal formulations for DHA and EPA remain unclear.

\section{INTRODUCTION}

An interest in the therapeutic use of n-3 polyunsaturated fatty acids (omega 3 fats, or fish oil) to prevent and treat cardiovascular diseases began after a report in 1976 showed that the high consumption of fish oil in Inuit living in Greenland was associated with a decreased risk of cardiovascular disease. ${ }^{1}$ The GISSIPrevenzione trial ${ }^{\mathrm{w} 1}$ of 11324 patients randomised to a mixture of the omega 3 fats eicosapentaenoic acid (EPA) and docosahexaenoic acid (DHA, 850-882 mg/ day in a ratio of $1.2: 1$, respectively) or placebo showed a significant reduction in all cause mortality and death from cardiovascular causes over 3.5 years of follow-up. These results seemed to be driven by a reduction in sudden cardiac death, sparking an interest in the potential antiarrhythmic properties of fish oil. Three recent randomised clinical trials looked at fish oil in the prevention of sudden cardiac death in patients with implantable cardiac defibrillators. ${ }^{\text {w2-w4 }}$ None of these trials, or a recent systematic review, ${ }^{2}$ showed a beneficial effect of fish oil on patient outcomes. This may be because of methodological limitations such as overly optimistic estimates of effect sizes, poor patient adherence to the treatment regimen, and high losses to follow-up (all contributing to reduced study power), and the use of different formulations of fish oil (content of EPA and DHA). DHA has been reported to accumulate preferentially over EPA in the plasma membrane of cardiac myocytes. ${ }^{34}$ This might confer a different effect on stabilising the membrane by changing its physical, electrical, and chemical properties. This might also result in DHA having a different influence on cardiac ion channels. In addition, both EPA and DHA are known to inhibit sodium channels, and DHA also inhibits $\mathrm{K}_{\mathrm{v}}$ and $\mathrm{K}_{\mathrm{ir}}$ channels, which are involved in depolarisation and repolarisation of cardiac cells. This might result in different antiarrhythmic properties for each fatty acid. ${ }^{5-7} \mathrm{We}$ evaluated the effect of EPA and DHA on all cause mortality and deaths from cardiac causes based on the formulation of these compounds. Previous systematic reviews are inconclusive as they do not include the most recent studies. ${ }^{8}$ Given the clinical and public health importance of sudden cardiac death, and the lack of clear evidence on the benefit of fish oil in this 


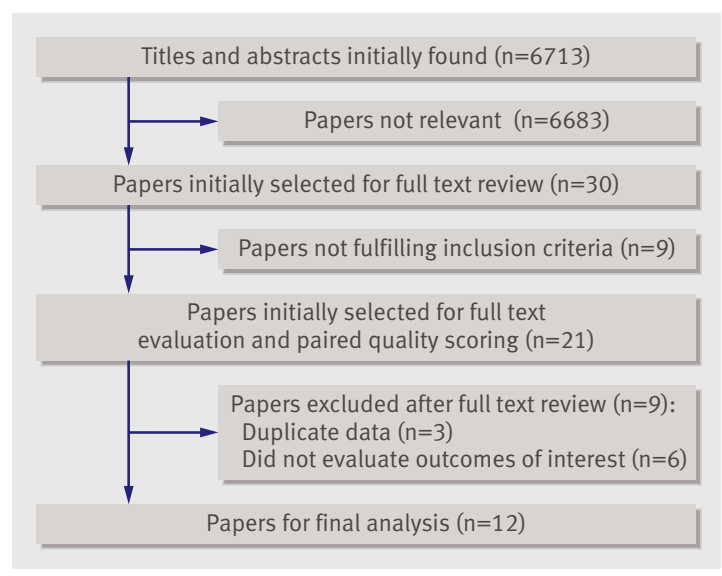

Fig 1| Flow of papers through review

population, we systematically examined the association between fish oil and arrhythmic events.

\section{METHODS}

We followed the procedures outlined by the Cochrane Collaboration for systematic reviews. ${ }^{9}$ In November 2006 two librarians (MD and TC) searched Medline (1966-2006), Embase (1988-2006), the Cochrane Library, PubMed, CINAHL (1982-October 2006), IPA (1970-October 2006), Web of Science, Scopus, Pascal (1987-September 2006), Allied and Complementary Medicine (1985-October 2006), Academic OneFile, ProQuest Dissertations and Theses, Evidence-Based Complementary Medicine, and LILACS using relevant subject headings, Chemical Abstracts Service registry numbers, and a collection of text words representing the concepts of fish oil and cardiac death: "Fish oil", "omega-3 fatty acids", "docosahexaenoic acid", "eicosapentaenoic acid," "docosahexanoic acid", "eicosapentanoic acid", "DHA", "EPA", "unsaturated fatty acid", "N3 fatty acids", "omega fatty acids", "polyunsaturated", "PUFA", "icosapentaenoic acid", "sudden cardiac death", "cardiac sudden death", "ventricular tachycardia", "arrhythmogenic right ventricular dysplasia", "torsades de pointes", "ventricular fibrillation", "heart arrest", "myocardial infarction", "cardiovascular disease", "heart disease", "coronary disease", "heart attack", "heart death", "heart arrhythmia", "heart infarction", "cardiac death", and "coronary artery disease". The terms were not used in every resource-for instance, spellings of words depended on whether American or European databases were being searched. No language restriction was applied. When appropriate we exploded subject headings and truncated terms. The searches in some databases were limited by intrinsic restrictions of those resources-for example, maximum counts for characters. Otherwise, we used strategies as comprehensive as possible. To identify additional papers we reviewed a collection of articles on heart disease and omega 3 fatty acids from the IBIDS database and reference lists of included studies. In March 2007 we updated the search to reduce publication bias as much as possible.
We included studies that tested fish oil as dietary supplements in humans in a randomised controlled trial setting. Trials were excluded if they did not report any of the outcomes of interest, were not randomised, included pregnant women or children, or lasted less than three months.

\section{Outcomes, data collection, and quality assessment}

The primary outcomes of interest were the arrhythmic end points of appropriate implantable cardiac defibrillator intervention (confirmed by electrogram) and sudden cardiac death. The secondary outcomes were all cause mortality and death from cardiac causes. Subgroup analyses included the effect of formulations of EPA and DHA on deaths from cardiac causes and effects of fish oil in patients with coronary artery disease or myocardial infarction.

Search results were reviewed to select potentially relevant abstracts. Two investigators, blinded to publication source and authors' names, independently reviewed the selected abstracts. A third reviewer acted as mediator to resolve any discrepancies. The full text of relevant abstracts was obtained. A data collection form was created and used by two investigators to extract information independently and systematically on the outcomes of interest, inclusion criteria, the risk of bias, and interventions. To ensure accuracy of this procedure the two reviewers compared collected data. A third reviewer acted as mediator for discrepancies.

Two reviewers independently assessed the quality of each study using a form derived from the Jadad criteria. ${ }^{10}$ In addition, we evaluated other criteria such as concealment of treatment allocation, ${ }^{11}$ funding agencies, and use of intention to treat analysis.

\section{Statistical analysis}

Data were entered into $2 \times 2$ tables. We used RevMan 4.2.9 (Cochrane, Copenhagen, Denmark) to analyse results. Data are presented as odds ratios with $95 \%$ confidence intervals, using the DerSimonian and Laird random effects model. A value of 0.5 was automatically inserted by the statistical software to allow for reporting of zero events in a category. Agreement between reviewers was measured using kappa analysis and the results were reported using the Cohen kappa index. ${ }^{12}$ For evaluation of heterogeneity we used both the $\chi^{2}$ test and the $\mathrm{I}^{2}$ test. The $\mathrm{z}$ test was used to determine overall effect. Assessment of publication bias was carried out by generating a funnel plot from the end points that showed a significant benefit from fish oil.

\section{Dose-response analysis}

To evaluate whether a dose-response exists with EPA or DHA we carried out a meta-regression analysis using the random effects model for meta-analysis regression, and analysed the data using STATA software. For this analysis we used the outcome of deaths from cardiac causes, as it was the clinical outcome that was statistically significantly different in the main analyses. 


\section{Assessment of safety versus efficacy of fish oil}

We evaluated the relative risk of a non-cardiovascular adverse effect occurring in patients who received fish oil compared with placebo. We also expressed treatment effects and adverse effects using the numbers needed to treat to reduce one significant clinical event and numbers needed to harm for an adverse effect.

\section{RESULTS}

An initial search retrieved 6713 titles and abstracts, from which 6683 editorials, reviews, letters, nonrandomised trials, and studies in animals were excluded. Of the 30 abstracts selected as potentially relevant for review of the full text, nine papers were excluded for not meeting the inclusion criteria, with an agreement by $\kappa$ coefficient of 0.92 . Therefore 21 papers were considered for data collection and evaluated by two reviewers, with $100 \%$ agreement for quality assessment. After excluding three papers with duplicate data ${ }^{13-15}$ and six for not evaluating an outcome of interest, ${ }^{16-21} 12$ studies were included in the final analysis (fig 1). ${ }^{\text {w-w12 }}$

Five of the 12 studies scored 5 for methodological quality on the Jadad scale, four scored 4, two scored 3, and one scored 2 . The table lists the characteristics of the included studies.

\section{Primary outcomes}

Three studies included 1148 patients with implantable cardiac defibrillators who received fish oil or placebo (fig 2). Fish oil supplementation reduced the risk of appropriate implantable cardiac defibrillator intervention by a non-significant $10 \%$ (odds ratio $0.90,95 \%$ confidence interval 0.55 to 1.46$)$. Six studies, totalling 31111 patients, evaluated the effect of fish oil on the incidence of sudden cardiac death (fig 2). A non-significant reduction in sudden cardiac death was observed (odds ratio $0.81,0.52$ to $1.25)$

\section{Secondary outcomes}

Death from cardiac causes was evaluated in 11 studies involving 32519 patients and showed a significant $20 \%$ decrease in events (odds ratio $0.80,0.69$ to 0.92 ; fig 3 ). The funnel plot, however, shows a partially skewed pattern that suggests some publication bias (fig 4). Eleven studies evaluated all cause mortality in a total of 32439 patients and showed a non-significant 8\% reduction (odds ratio $0.92,0.82$ to 1.03 ). These results were driven primarily by two trials: the GISSIPrevenzione trial, and the JELIS trial on the effects of EPA on major coronary events in patients with hypercholesterolaemia (fig 5). ${ }^{\text {w1 w5 }}$

\begin{tabular}{|c|c|c|c|c|c|c|c|c|c|}
\hline Characteristic & s of included studies on 0 & nega 3 & ts eicosape & noic ac & (EPA) and & osahexaenoic acid & (DHA) & & \\
\hline & & Trea & ent group & $\mathrm{Co}$ & ol group & & & & \\
\hline Study & Population & No & $\begin{array}{l}\text { Mean (SD) } \\
\text { age (years) }\end{array}$ & No & $\begin{array}{l}\text { Mean (SD) } \\
\text { age (years) }\end{array}$ & $\begin{array}{c}\text { EPA and DHA (mg/ } \\
\text { day) }\end{array}$ & Control & Follow-up (months) & $\begin{array}{l}\text { Quality } \\
\text { score* }\end{array}$ \\
\hline Brouwer et al ${ }^{\mathrm{w} 4}$ & $\begin{array}{l}\text { Implantable cardiac } \\
\text { defibrillation }\end{array}$ & 273 & $60.5(12.5)$ & 273 & $62.4(11.4)$ & 464 and 335 & $\begin{array}{l}2 \mathrm{~g} \text { of high oleic acid } \\
\text { sunflower oil }\end{array}$ & $\begin{array}{l}12 \text { or until trial } \\
\text { ended (January } \\
\text { 2005) }\end{array}$ & 5 \\
\hline Calo et al'w6 & $\begin{array}{l}\text { After coronary artery bypass } \\
\text { grafting }\end{array}$ & 79 & $66.2(8)$ & 81 & $64.9(9)$ & $\begin{array}{c}\text { 568-588 and } 1132- \\
1176\end{array}$ & $\begin{array}{l}\text { Conventional } \\
\text { treatment }\end{array}$ & 1 & 3 \\
\hline $\begin{array}{l}\text { Durrington et } \\
\mathrm{al}^{\mathrm{w} 7}\end{array}$ & $\begin{array}{l}\text { Coronary artery disease and } \\
\text { increased triglyceride levels }\end{array}$ & 30 & $55.2(7)$ & 29 & $54.8(10.2)$ & 880 and 732 & Corn oil & 6 & 4 \\
\hline GISSI-Prev $^{\text {w1 }}$ & $\begin{array}{l}\text { Two weeks after myocardial } \\
\text { infarction }\end{array}$ & 5666 & NA & 5668 & NA & $\begin{array}{c}\text { 463.6-481.1 and } \\
386.4-400.9\end{array}$ & No placebo & 42 & 4 \\
\hline $\begin{array}{l}\text { Johansen et } \\
\mathrm{al}^{\mathrm{w} 8}\end{array}$ & $\begin{array}{l}\text { Elective percutaneous } \\
\text { coronary angioplasty }\end{array}$ & 250 & $60.3(9.3)$ & 250 & $59.1(9.3)$ & 2700 and 2340 & Corn oil & 6 & 5 \\
\hline Leaf et al ${ }^{\mathrm{w} 3}$ & $\begin{array}{l}\text { Implantable cardiac } \\
\text { defibrillation }\end{array}$ & 200 & $65.7(0.8)$ & 202 & $65.3(0.3)$ & 18.2 and 2361 & 4 g olive oil & 12 & 5 \\
\hline Nilsen et $\mathrm{al}^{\mathrm{w} 9}$ & $\begin{array}{l}\text { First week after myocardial } \\
\text { infarction }\end{array}$ & 150 & NA & 150 & NA & $\begin{array}{c}1136-1176 \text { and } \\
2264-2352\end{array}$ & Corn oil & $\begin{array}{l}\text { Up to } 24 \text { (median } \\
18 \text { ) }\end{array}$ & 3 \\
\hline Raitt et al ${ }^{\mathrm{w} 2}$ & $\begin{array}{l}\text { Implantable cardiac } \\
\text { defibrillation }\end{array}$ & 100 & $63(13)$ & 100 & $62(13)$ & 756 and 540 & $\begin{array}{l}\text { Olive oil: } 73 \% \text { oleic } \\
\text { acid, } 12 \% \text { palmitic } \\
\text { acid }\end{array}$ & $\begin{array}{l}24 \text { or to end of July } \\
2003\end{array}$ & 5 \\
\hline Sacks et al ${ }^{w 10}$ & $\begin{array}{l}\text { Percutaneous coronary } \\
\text { angioplasty }\end{array}$ & 31 & $62(7)$ & 28 & $62(7)$ & 2800 and 1920 & Olive oil & 28.8 & 4 \\
\hline Singh et al ${ }^{w 11}$ & Acute myocardial infarction & 122 & $48.5(6.5)$ & 118 & $49.2(7.2)$ & 1080 and 720 & $\begin{array}{l}100 \text { mg aluminium } \\
\text { hydroxide }\end{array}$ & 12 & 4 \\
\hline $\begin{array}{l}\text { Von Schacky et } \\
\mathrm{al}^{\mathrm{w} 12}\end{array}$ & $\begin{array}{l}\text { Percutaneous coronary } \\
\text { angioplasty }\end{array}$ & 111 & $57.8(10)$ & 112 & $58.9(8.1)$ & $\begin{array}{c}2120 \text { for } 3 \text { months, } \\
1060 \text { for } 21 \text { months } \\
\text { and } 1290 \text { for } \\
3 \text { months, } 510 \text { for } \\
21 \text { months }\end{array}$ & $\begin{array}{l}\text { Mixture of fatty acids } \\
\text { without EPA and } \\
\text { DHA }\end{array}$ & 24 & 5 \\
\hline $\mathrm{JELIS}^{\mathrm{w} 5}$ & $\begin{array}{l}\text { Primary prevention about } \\
90 \% \text {, secondary prevention } \\
\text { about } 10 \% \text { with } \\
\text { hypercholesterolaemia }\end{array}$ & 9326 & $61(8)$ & 9319 & $61(9)$ & 1764 and 0 & No placebo & $\begin{array}{c}60 \text { or until } \\
\text { November } 2004\end{array}$ & 2 \\
\hline
\end{tabular}




\begin{tabular}{|c|c|c|c|c|c|c|}
\hline \multirow[b]{2}{*}{ Study and subcategory } & \multicolumn{2}{|c|}{$\begin{array}{l}\text { No with event/ } \\
\text { No in group }\end{array}$} & \multirow{2}{*}{\multicolumn{2}{|c|}{$\begin{array}{c}\text { Odds ratio } \\
\text { (random) }(95 \% \mathrm{Cl})\end{array}$}} & \multirow{3}{*}{$\begin{array}{c}\text { Weight } \\
\text { (\%) }\end{array}$} & \multirow[b]{2}{*}{$\begin{array}{c}\text { Odds ratio } \\
\text { (random) }(95 \% \mathrm{Cl})\end{array}$} \\
\hline & Fish oil & Placebo & & & & \\
\hline \multicolumn{3}{|c|}{ Implantable cardiac defibrillator intervention } & \multirow{3}{*}{$\longrightarrow$} & \multirow[b]{3}{*}{ - } & & \\
\hline Leaf et al $2005^{\mathrm{w} 3}$ & $44 / 200$ & $66 / 202$ & & & 33.86 & 0.58 (0.37 to 0.91$)$ \\
\hline Raitt et al $2005^{\mathrm{w} 2}$ & $51 / 100$ & $41 / 100$ & & & 26.75 & 1.50 (0.86 to 2.62$)$ \\
\hline Brouwer et al $2006^{\mathrm{w} 4}$ & $75 / 273$ & $81 / 273$ & & & 39.39 & 0.90 (0.62 to 1.30$)$ \\
\hline Total $(95 \%$ Cl) & 573 & 575 & & & 100.00 & $0.90(0.55$ to 1.46$)$ \\
\hline \multicolumn{7}{|c|}{ Total events: 170 (fish oil), 188 (placebo) } \\
\hline \multicolumn{7}{|c|}{ Test for heterogeneity: $\chi^{2}=6.81, \mathrm{df}=2, \mathrm{P}=0.03, \mathrm{I}^{2}=70.6 \%$} \\
\hline \multicolumn{7}{|c|}{ Test for overall effect: $z=0.43, P=0.67$} \\
\hline \multicolumn{7}{|l|}{ Sudden cardiac death } \\
\hline Singh et al $1997^{\mathrm{w11}}$ & $2 / 122$ & $8 / 118$ & + & & 6.47 & 0.23 (0.05 to 1.10$)$ \\
\hline GISSI-Prevenzione $1999^{\text {w1 }}$ & $122 / 5666$ & $164 / 5658$ & & & 60.77 & 0.74 (0.58 to 0.93$)$ \\
\hline Nilsen et al $2001^{\text {w9 }}$ & $0 / 150$ & $1 / 150$ & $\longleftarrow$ & & 1.66 & 0.33 (0.01 to 8.19$)$ \\
\hline Leaf et al $2005^{\mathrm{w} 3}$ & $3 / 200$ & $1 / 202$ & & $\longleftrightarrow$ & 3.24 & 3.06 (0.32 to 29.68$)$ \\
\hline Raitt et al $2005^{\mathrm{w} 2}$ & $2 / 100$ & $0 / 100$ & & & 1.83 & $5.10(0.24$ to 107.62 \\
\hline JELIS $2007^{\mathrm{W} 5}$ & $18 / 9326$ & $17 / 9319$ & & - & 26.02 & 1.06 (0.55 to 2.05$)$ \\
\hline Total $(95 \% \mathrm{Cl})$ & 15564 & 15547 & & & 100.00 & 0.81 (0.52 to 1.25$)$ \\
\hline \multicolumn{7}{|c|}{ Total events: 147 (fish oil), 191 (placebo) } \\
\hline \multicolumn{3}{|c|}{ Test for heterogeneity: $\chi^{2}=6.45, \mathrm{df}=5, \mathrm{P}=0.26, \mathrm{I}^{2}=22.5 \%$} & 0.2 & 2 & & \\
\hline \multicolumn{3}{|c|}{ Test for overall effect: $\mathrm{z}=0.97, \mathrm{P}=0.33$} & Favours fish oil & Favours placebo & & \\
\hline
\end{tabular}

Fig 2 Effect of fish oil on appropriate implantable cardiac defibrillator intervention and sudden cardiac death

A meta-regression analysis did not show a doseresponse relation between DHA and EPA and death from cardiac causes.

A subgroup analysis was done on the effect of fish oil on sudden cardiac death and death from cardiac causes in patients with coronary artery disease or after myocardial infarction, including the secondary prevention arm of the JELIS trial. ${ }^{\text {w5 }}$ Four studies that included 15528 patients showed a $26 \%$ reduction $(0.74,0.59$ to 0.92$)$ in sudden cardiac death with fish oil (fig 6). Eight studies with 16390 patients showed a significant $20 \%$ reduction in deaths from cardiac causes compared with placebo $(0.80,0.69$ to 0.93$)$ in patients with coronary artery disease or after myocardial infarction (fig 6).

Two different approaches were used to compare the safety and efficacy profiles for fish oil to reduce deaths from cardiac causes. The incidence of adverse effects was $10.5 \%$ in patients who took fish oil compared with $6.7 \%$ in those who took placebo. Patients taking fish oil are therefore $56 \%$ more likely to experience an adverse effect than those taking placebo. However, most of these effects were described as mild. This corresponds to a number needed to treat with fish oil to reduce one death from cardiac causes of 189 , and a number needed to harm of 26 .

\begin{tabular}{|c|c|c|}
\hline & & \\
\hline Study & Fish oil & Placebo \\
\hline Sacks et al $1995^{\mathrm{w} 10}$ & $0 / 41$ & $1 / 39$ \\
\hline Singh et al $1997^{\mathrm{w} 11}$ & $14 / 122$ & $26 / 118$ \\
\hline GISSI-Prevenzione $1999^{\text {w1 }}$ & $291 / 5666$ & $348 / 5658$ \\
\hline Johansen et al $1999^{\text {w8 }}$ & $1 / 250$ & $3 / 250$ \\
\hline Von Shacky et al $1999^{\text {w12 }}$ & $0 / 111$ & $1 / 112$ \\
\hline Durrington et al $2001^{\mathrm{w} 7}$ & $0 / 30$ & $1 / 29$ \\
\hline Nilsen et al $2001^{\text {w9 }}$ & $8 / 150$ & $8 / 150$ \\
\hline Leaf et al $2005^{\mathrm{w} 3}$ & $9 / 200$ & $9 / 202$ \\
\hline Raitt et al $2005^{\mathrm{w} 2}$ & $2 / 100$ & $5 / 100$ \\
\hline Brouwer et al $2006^{\mathrm{w} 4}$ & $6 / 273$ & $13 / 273$ \\
\hline JELIS $2007^{\mathrm{w} 5}$ & $29 / 9326$ & $31 / 9319$ \\
\hline Total $(95 \% \mathrm{Cl})$ & 16269 & 16250 \\
\hline Total events: 360 (fish oil), & cebo) & \\
\hline Test for heterogeneity: $\chi^{2}=6$ & $10, P=0.7$ & \\
\hline Test for overall effect: $z=3.0$ & 002 & \\
\hline
\end{tabular}

Fig 3 Effect of fish oil on death from cardiac causes

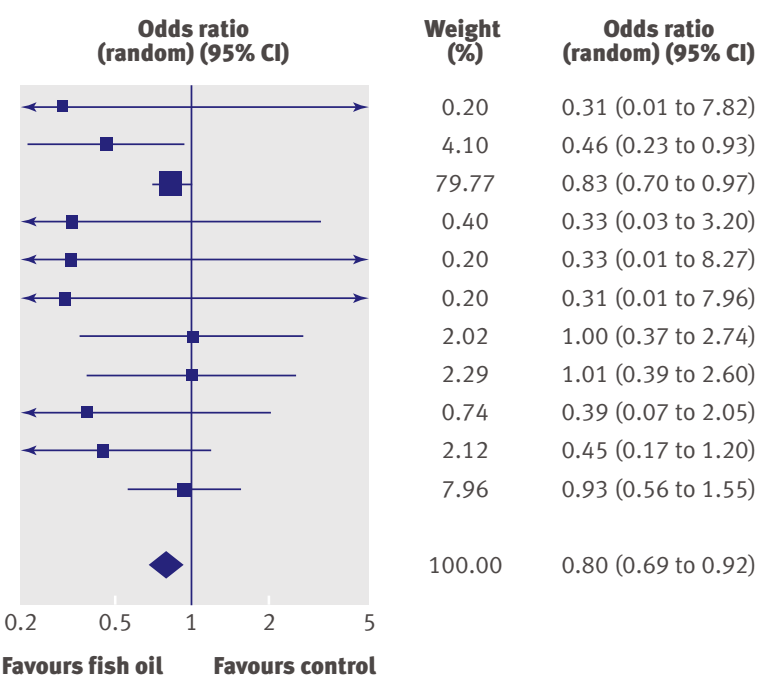




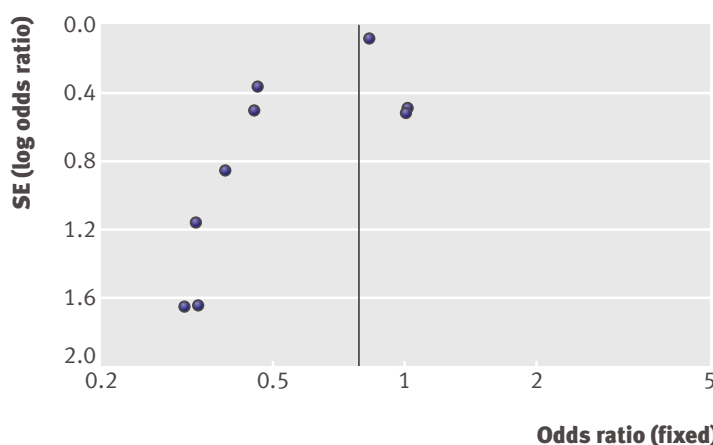

Fig 4 | Funnel plot for assessment of publication bias for death from cardiac causes in 11 included studies reporting data on this outcome

\section{DISCUSSION}

Our systematic review of randomised trials of fish oil supplementation showed no beneficial effect on arrhythmic events or all cause mortality but a significant reduction in deaths from cardiac causes. This is in contrast to the results of the GISSIPrevenzione trial, ${ }^{\mathrm{w} 1}$ which suggested that the beneficial effect on death was due primarily to a reduction in sudden cardiac death.

This is the first systematic review attempting to evaluate whether the protective mechanism of fish oil supplementation is related to a reduction of arrhythmic episodes determined either by a reduction in implantable cardiac defibrillator interventions or a reduction in sudden cardiac death. We found a neutral effect on these two outcomes. The confidence intervals for these outcomes were wide and a beneficial effect up to a 45 $48 \%$ relative risk reduction cannot be excluded. Some heterogeneity was found among the three studies that assessed implantable cardiac defibrillator intervention (see fig 2). Also, regardless of the high quality scores of these studies, differences among them were substantial, including dosages of fish oil and important differences in study power. Our data support the recent analysis by Jenkins et $\mathrm{al}^{2}$ which focused on implantable cardiac defibrillator interventions only. In light of currently available evidence the role of fish oil in reducing arrhythmic events in people at risk still remains to be elucidated.

Our analysis showed a highly variable effect of fish oil supplementation on sudden cardiac death, varying from a $48 \%$ reduction in events to a $25 \%$ increase (fig 2 ). These results were mainly driven by two studies, the GISSI-Prevenzione and JELIS trials. ${ }^{\mathrm{w} 1 \text { w5 }}$ GISSI-Prevenzione was a secondary prevention study in patients after myocardial infarction with a moderate fish intake and mainly DHA supplementation, ${ }^{\text {w1 }}$ whereas the JELIS trial included patients with hypercholesterolaemia for both primary and secondary prevention who had a high fish intake, received statins, and received only EPA supplementation. ${ }^{\mathrm{w} 5}$ The role and perhaps interaction of statins and fish consumption with fish oil supplementation need further study.

We observed a significant 20\% reduction in deaths from cardiac causes. This is similar to previous systematic reviews that included studies of dietary intake of fish oil either by increased intake or supplementation, which showed a significant reduction in cardiovascular events (including strokes). Most of these events were, however, related mainly to a reduction in deaths from coronary events with a reduction in risk ranging from $24 \%$ to $36 \%{ }^{822-24}$ Experimental studies have proposed that fish oil helps to stabilise the atherosclerotic plaque through several mechanisms, which include anti-inflammatory properties (production of fewer inflammatory prostaglandins and leukotrienes), inhibition of lipoprotein lipase in the atherosclerotic plaque, and selective uptake of low density lipoprotein cholesterol, inhibition of transcription factors such as NF- $\kappa \mathrm{B}$ gene that is

\begin{tabular}{|c|c|c|}
\hline \multirow[b]{2}{*}{ Study } & \multicolumn{2}{|c|}{$\begin{array}{l}\text { No with event/ } \\
\text { No in group }\end{array}$} \\
\hline & Fish oil & Placebo \\
\hline Sacks et al $1995^{\text {w10 }}$ & $0 / 41$ & $1 / 39$ \\
\hline GISSI-Prevenzione $1999^{\text {w1 }}$ & $472 / 5666$ & $545 / 5658$ \\
\hline Johansen et al $1999^{w 8}$ & $1 / 250$ & $3 / 250$ \\
\hline Von Shacky et al $1999^{\text {w12 }}$ & $1 / 111$ & $1 / 112$ \\
\hline Durrington et al $2001^{\mathrm{w} 7}$ & $0 / 30$ & $1 / 29$ \\
\hline Nilsen et al $2001^{\text {w9 }}$ & $11 / 150$ & $11 / 150$ \\
\hline Calo et al $2005^{\mathrm{w} 6}$ & $1 / 79$ & $2 / 81$ \\
\hline Leaf et al $2005^{\mathrm{w} 3}$ & $13 / 200$ & $12 / 202$ \\
\hline Raitt et al $2005^{\mathrm{w} 2}$ & $4 / 100$ & $10 / 100$ \\
\hline Brouwer et al $2006^{w 4}$ & $8 / 273$ & $14 / 273$ \\
\hline JELIS $2007^{\mathrm{w} 5}$ & $286 / 9326$ & $265 / 9319$ \\
\hline Total $(95 \% \mathrm{Cl})$ & 16226 & 16213 \\
\hline \multicolumn{3}{|c|}{ Total events: 797 (fish oil), 865 (placebo) } \\
\hline \multicolumn{3}{|c|}{ Test for heterogeneity: $\chi^{2}=10.30, \mathrm{df}=10, \mathrm{P}=0.41, \mathrm{I}^{2}=2.9 \%$} \\
\hline \multicolumn{3}{|c|}{ Test for overall effect: $z=1.48, P=0.14$} \\
\hline
\end{tabular}

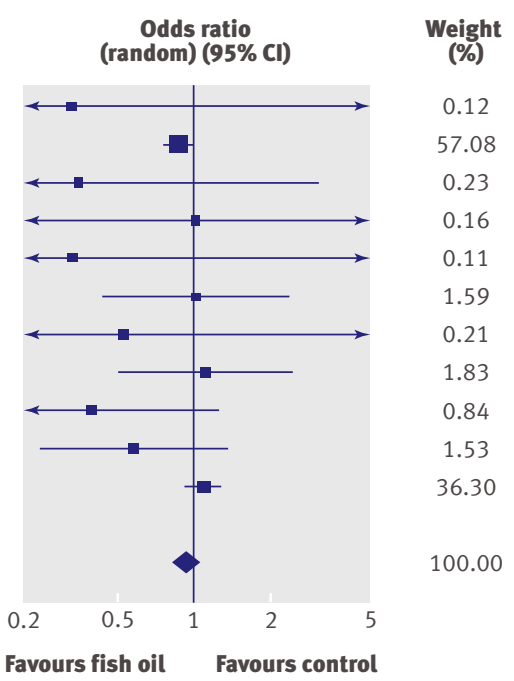
Odds ratio (random) $(95 \% \mathrm{Cl})$
0.31 (0.01 to 7.82$)$
0.85 (0.75 to 0.97$)$
$0.33(0.03$ to 3.20$)$
1.01 (0.06 to 16.34$)$
0.31 (0.01 to 7.96$)$
$1.00(0.42$ to 2.38$)$
$0.51(0.05$ to 5.70$)$
$1.10(0.49$ to 2.47$)$
0.38 (0.11 to 1.24$)$
$0.56(0.23$ to 1.35$)$
1.08 (0.91 to 1.28$)$

$0.92(0.82$ to 1.03$)$ 


\begin{tabular}{l} 
Study \\
Sudden cardiac death in patients with coronary artery disease \\
\cline { 2 - 5 }
\end{tabular}

Fig 6 | Effect of fish oil on sudden cardiac death and death from cardiac causes in patients with coronary artery disease

related to upregulation of proinflammatory cytokines, matrix metalloproteinases (specifically MMP-9), and chemokines. ${ }^{2526}$ In addition, fish oil reduces the activity of the CD-40 system that plays an important part in rupture of atherosclerotic plaque through actions on platelet activation and stimulating NF- $\kappa \mathrm{B}$ gene. ${ }^{27} \mathrm{~A}$ recent clinical study found a reduction of MMP-9 and sCD4L as well as an increase in plasma levels of pregnancy associated plasma protein $\mathrm{A}$ in patients after myocardial infarction randomised to receive two tablets of 850-882 $\mathrm{mg}$ EPA and DHA mixture for one year. ${ }^{28}$ These changes were, however, similar between the groups that received corn oil or placebo. Therefore the potential mechanisms enabling fish oil to reduce deaths from cardiac causes remain elusive.

We did not find a significant reduction in all cause mortality, whereas previous reviews showed a significant reduction. ${ }^{822-24}$ The upper limit of the confidence interval was only 1.03 , which might represent a lack of power for this end point. We also excluded studies on dietary supplementation.

Although a wide variety of fish oil products with various formulations have been studied, we did not observe a dose-response relation for effect on deaths from cardiac causes according to dosage of EPA or DHA. Therefore an ideal formulation for fish oil supplementation cannot be determined with the currently available evidence.

We also evaluated the adverse effect profile of fish oil. The use of fish oil supplements is associated with a higher prevalence of adverse reactions; these were mild, however, consisting mainly of diarrhoea or nausea. In addition, the wide variation in formulation and dosages among the trials may affect the incidence of adverse effects observed in our study. The trade-off for fewer deaths from cardiac causes is that one in 26 patients will develop mostly a mild gastrointestinal adverse effect. Recently it was reported that the most common adverse effects in patients with hypertriglyceridaemia who received fish oil $4 \mathrm{~g}$ /day compared with placebo in addition to simvastatin $40 \mathrm{mg}$ /day for eight weeks were nasopharyngitis (3.3\%), diarrhoea (2.5\%), dyspepsia (2.5\%), bronchitis, and cystitis; an increase in liver enzymes was observed in $1.6 \%$ of patients with each adverse event. ${ }^{29}$ Therefore it would be advisable to weigh the benefits and risks of using fish oil in patients with cardiovascular risk factors, especially those with baseline gastrointestinal disease.

\section{Limitations}

The results of this systematic review were driven primarily by two large, but different trials, GISSIPrevenzione and JELIS, ${ }^{\mathrm{w} 1}{ }^{\mathrm{w} 5}$ which together accounted for $92 \%$ of the patients. Nevertheless, our review was the first to include the JELIS trial, totalling more than 18000 patients. $^{\text {w5 }}$ Despite our detailed and comprehensive search strategy, the funnel plot showed a skewed pattern suggesting publication bias, whereby neutral or negative trials may not be published. 


\section{WHAT IS ALREADY KNOWN ON THIS TOPIC}

Fish oils are thought to be associated with a reduction in deaths from cardiac causes

Systematic reviews have been inconclusive and did not include recent studies

\section{WHAT THIS STUDY ADDS}

Fish oils had no significant effect on reduction in arrhythmic events but were associated with a significant reduction in deaths from cardiac causes

No evidence was found of a dose-response relation between type of fish oil and reduction in deaths from cardiac causes causes results from a reduction of arrhythmias or from a delay in the progression of coronary artery disease.

We thank Scot Simpson for his help with Rev Man Software, Jeppe Hagstrup Christensen (Aalborg Hospital, Aarhus University Hospital, Denmark) for sharing his results, and Ben Vandermeer for his help with the meta-regression analysis. No compensation of any kind was received by them for their help in preparing this manuscript. $\mathrm{HL}$ is a recipient of a research fellowship from the Alberta Heritage Foundation for Medical Research. RTT is supported by the University of Alberta Merck Frosst chair in patient health management.

Contributors: $\mathrm{HL}$ conceived and designed the study, collected and analysed or interpreted the data, and prepared the manuscript. MCS helped design the study, collect data, and revise the manuscript. SS helped collect and analyse the data and revise the manuscript. MD and TC helped design the study, especially the literature search, and revise the manuscript. RTT helped conceive and design the study, analyse the data, and revise the manuscript. RT and $\mathrm{HL}$ are guarantors of this paper.

Funding: None

Competing interests: None declared

Ethical approval: Not required

Provenance and peer review: Not commissioned; externally peer reviewed. of statistical heterogeneity among the outcomes measured. Significant heterogeneity $\left(\mathrm{I}^{2}=70.6 \%\right)$ was found among the implantable cardiac defibrillator trials, which might affect the validity of this analysis (see fig 2). The statistical heterogeneity shown in the forest plots for the other outcomes measured in our study are, however, relatively low.

Our analysis of appropriate implantable cardiac defibrillator intervention included 1148 patients from secondary prevention trials and showed a nonsignificant effect of fish oil that might be a type 2 error. If a new randomised controlled trial using one formulation of fish oil were designed to evaluate appropriate implantable cardiac defibrillator interventions in one year in patients with an implantable cardiac defibrillator for secondary prevention, assuming that $33 \%$ of these patients had an appropriate implantable cardiac defibrillator intervention per year, at least 1600 patients (without including losses to follow-up or drop-outs) would be required to observe a $20 \%$ reduction of events with an $80 \%$ power. Therefore our pooled analysis for this end point should be considered inconclusive on the basis of small sample size and noticeable heterogeneity among the trials.

\section{Implications for clinical practice}

Based on the best currently available evidence, the results of this systematic review show a beneficial effect of fish oil in reducing deaths from cardiac causes. The optimal dose or formulation of fish oil is unknown, but it seems reasonable to use a daily formulation similar to that used in the GISSI-Prevenzione trial, of about $465 \mathrm{mg}$ EPA/386 mg DHA. The effect of fish oil on arrhythmic events remains inconclusive.

\section{Conclusions}

On the basis of data from over 30000 patients, fish oil supplementation was associated with a significant reduction in deaths from cardiac causes but had no significant effect on arrhythmias. Ongoing trials, such as the OMEGA trial, ${ }^{30}$ and future studies might help to clarify whether the reduction in deaths from cardiac
1 Bang HO, Dyerberg J, Hjoorne N. The composition of food consumed by Greenland eskimos. Acta Med Scand 1976;200:69-73.

2 Jenkins DJ, Josse AR, Beyene J, Dorian P, Burr ML, LaBelle R, et al. Fishoil supplementation in patients with implantable cardioverter defibrillators: a meta-analysis. CMA/ 2008;178:157-64.

3 McLennan PL. Myocardial membrane fatty acids and the antiarrhythmic actions of dietary fish oil in animal models. Lipids 2001:36(suppl):S111-4

4 Charnock JS, Abeywardena MY, Poletti VM, McLennan PL. Differences in fatty acid composition of various tissues of the marmoset monkey (Callithrix jacchus) after different lipid supplemented diets. Comp Biochem Physiol Comp Physiol 1992;101:387-93.

5 Honore E, Barhanin J, Attali B, Lesage F, Lazdunski M. External blockade of the major cardiac delayed-rectifier $\mathrm{K}^{+}$channel (Kv1.5) by polyunsaturated fatty acids. Proc Natl Acad Sci USA 1994;91:1937-41.

6 Doolan GK, Panchal RG, Fonnes EL, Clarke AL, Williams DA, Petrou S. Fatty acid augmentation of the cardiac slowly activating delayed rectifier current (IKs) is conferred by hminK. FASEB J 2002;16:1662-4.

7 Singleton CB, Valenzuela SM, Walker BD, Tie H, Wyse KR, Bursill JA, et al. Blockade by N-3 polyunsaturated fatty acid of the Kv4.3 current stably expressed in Chinese hamster ovary cells. Br J Pharmacol 1999;127:941-8.

8 Hooper L, Thompson RL, Harrison RA, Summerbell CD, Ness AR, Moore HJ, et al. Risks and benefits of omega 3 fats for mortality, cardiovascular disease, and cancer: systematic review. $B M J$ 2006;332:752-60.

9 Higgins JPT Green S, eds. Cochrane handbook for systematic reviews of interventions 4.2.5 [updated May 2005]. www.cochrane.org/ resources/handbook/hbook.htm (accessed 31 May 2005).

10 Jadad AR, Moore RA, Carroll D, Jenkinson C, Reynolds DJ, Gavaghan DJ, et al. Assessing the quality of reports of randomized clinical trials: is blinding necessary? Control Clin Trials 1996;17:1-12.

11 Schulz KF. Subverting randomization in controlled trials. JAMA 1995;274:1456-8.

12 Cohen J. A coefficient of agreement for nominal scales. Educ Psych Meas 1960;20:37-46.

13 Geelen A, Zock PL, Brouwer IA, Katan MB, Kors JA, Ritsema van Eck HJ, et al. Effect of $n-3$ fatty acids from fish on electrocardiographic characteristics in patients with frequent premature ventricular complexes. BrJ Nutr 2005;93:787-90.

14 Grundt H, Nilsen DWT, Mansoor MA, Hetland O, Nordoy A. Reduction in homocysteine by $n-3$ polyunsaturated fatty acids after 1 year in a randomised double-blind study following an acute myocardial infarction: no effect on endothelial adhesion properties. Pathophysiol Haemost Thromb 2003;33:88-95.

15 Christensen JH, Gustenhoff P, Korup E, Aaroe J, Toft E, Moller JM, et al. [n-3 polyunsaturated fatty acids, heart rate variability and ventricular arrhythmias in post-AMI-patients. A clinical controlled trial]. Ugeskrift for Laeger 1997;159:5525-9.

16 Milner MR, Gallino RA, Leffingwell A, Pichard AD, Brooks-Robinson S, Rosenberg J, et al. Usefulness of fish oil supplements in preventing clinical evidence of restenosis after percutaneous transluminal coronary angioplasty. Am J Cardiol 1989;64:294-9.

17 Thies F, Garry JMC, Yaqoob P, Rerkasem K, Williams J, Shearman CP, et al. Association of $n-3$ polyunsaturated fatty acids with stability of atherosclerotic plaques: a randomised controlled trial. Lancet 2003;361:477-85. 
18 Geelen A, Brouwer IA, Schouten EG, Maan AC, Katan MB, Zock PL. Effects of $n-3$ fatty acids from fish on premature ventricular complexes and heart rate in humans. Am J Clin Nutr 2005;81:416-20.

19 Christensen JH, Gustenhoff P, Ejlersen E, Jessen T, Korup E, Rasmussen K, et al. n-3 fatty acids and ventricular extrasystoles in patients with ventricular tachyarrhythmias. Nutr Res 1995;15:1-8.

20 Singer $P$, Wirth M. Can n-3 PUFA reduce cardiac arrhythmias? Results of a clinical trial. Prostaglandins Leukot Essent Fatty Acids 2004;71:153-9.

21 Singer P, Wirth M. [Fish oil reduces cardiac arrhythmias-importance for diminishing reinfarction and sudden cardiac death.] Medizinische Welt 2003;54:68-74.

22 Yzebe D, Lievre M. Fish oils in the care of coronary heart disease patients: a meta-analysis of randomized controlled trials. Fundam Clin Pharmacol 2004;18:581-92.

23 Mozaffarian D, Rimm EB. Fish intake, contaminants, and human health: evaluating the risks and the benefits. JAMA 2006;296:1885-99.

24 Bucher HC, Hengstler P, Schindler C, Meier G. N-3 polyunsaturated fatty acids in coronary heart disease: a meta-analysis of randomized controlled trials. Am J Med 2002;112:298-304.

25 Calder PC. Polyunsaturated fatty acids and inflammation. Biochem Soc Trans 2005;33:423-7.
26 Torrejon C, Jung UJ, Deckelbaum RJ. n-3 Fatty acids and cardiovascular disease: actions and molecular mechanisms. Prostaglandins Leukot Essent Fatty Acids 2007;77:319-26.

27 Weatherill AR, Lee JY, Zhao L, Lemay DG, Youn HS, Hwang DH. Saturated and polyunsaturated fatty acids reciprocally modulate dendritic cell functions mediated through TLR4. J Immunol 2005;174:5390-7.

28 Aarsetoy H, Brugger-Andersen T, Hetland O, Grundt H, Nilsen DW. Long term influence of regular intake of high dose n-3 fatty acids on CD40-ligand, pregnancy-associated plasma protein A and matrix metalloproteinase-9 following acute myocardial infarction. Thromb Haemost 2006;95:329-36.

29 Davidson MH, Stein EA, Bays HE, Maki KC, Doyle RT, Shalwitz RA, et al. Efficacy and tolerability of adding prescription omega- 3 fatty acids $4 \mathrm{~g} / \mathrm{d}$ to simvastatin $40 \mathrm{mg} / \mathrm{d}$ in hypertriglyceridemic patients: an 8week, randomized, double-blind, placebo-controlled study. Clin Ther 2007;29:1354-67.

30 Rauch B, Schiele R, Schneider S, Gohlke H, Diller F, Gottwik M, et al. Highly purified omega-3 fatty acids for secondary prevention of sudden cardiac death after myocardial infarction-aims and methods of the OMEGA-study. Cardiovasc Drugs Ther 2006;20:365-75.

Accepted: 1 October 2008 